\title{
Inquiry of conflict of recognition of the value on trend of economic integration
}

\author{
Dali Li \\ Luohe Medical College \\ Luohe,462000 China
}

\begin{abstract}
Economic globalization has greatly expanded the living space of human civilization; it provides values coexistence and broad basement of identity. Currently, this identity mainly refers to identity "the sense of dominant values", its features are non-performance, dynamic and relative. While Economic globalization is strengthening the value of identity, it doesn't diminish value conflicts. This conflict is a cross-border, regional and national, regional conflicts affect is broader and more subtle, more acute contradictions. Recognition of the value is interpenetrated with conflict under the background of economic globalization, they are integrated and indivisible. To correct the recognition and treatment of this conflict, exploring the construction of the mechanism in line with the values of the world's cultural development trend of China's transition is extremely important.
\end{abstract}

Keywords- economic globalization; recognition of the value; value conflicts

\section{INTRODUCTION}

The essence and characteristics of recognition of the value Recognition of the value mentioned here, there are two levels of meaning: one refers to the common pursuit of mankind, that is commonly accepted by mankind, with the universality of humanity, it beyond the common values of specific boundaries, ethnicity, and body, some scholars have termed it for "universal values." The other is a worldwide leading value; it is in the core position in a multi-level and diversified system, which serves as a guide value. The former identity is flat, fully consistent identity; the latter is based on differences in the recognition of three-dimensional. Dominant value does not deny the value of the difference, it only represents general direction of the system which consists of various points, and it plays a role of commander on the other subordinate value. Regardless of the level of recognition of the value, its common meaning lies in people regulate their own actions with a certain value as a standard in their social practices, they regard common ideals, beliefs, standards, principles as their pursuit of goals, and consciously internalized into their own values. Some scholars have classified identity into "mandatory identity" and "lure identity" in two categories the background of economic globalization. It is said that: the former is the West, which forced the non-Western countries into their value system with its superiority of economic and military and technology; the latter is a non-mandatory way to bring people in non-Western countries into its architecture. (The author believes that the two agreements are not what a real identity is. The real identity should be established on the basis of the body conscious. Only the development of economic globalization to a certain extent, can the recognition built on the basis of the value of the body achieve possibly.

The essence of economic globalization is that human social life beyond the boundaries of countries and regions, showing the full range of communications and contacts worldwide. This communication and contact is bound to extend from the economic to cultural fields irresistibly. Economic dependence at national, regional conflict is bound to promote values, interaction and convergence. In this regard, we can analyze from the following aspects: First, the global economy overall association is promoting the values of identity. Globalizations of the world economy promote the values of people's identity by the growing worldwide association of means of social production. Secondly, the global drive of the interests promotes the values agreement. With strengthening that the economic globalization process beyond the common interests of all ethnic groups and all classes ,the degree of growing worldwide recognition of the values of the is higher. Thirdly, economic globalization is bound to drive values of identity to the full range. Economic globalization bringing more and more common habits for national style fashion ,lifestyles, consumption patterns and the way of thinking, it provides way for worldwide recognition undoubtedly.

In short, economic globalization highlights people's class consciousness, it is prompting people to understand the issues of common values by standing in the height of human development. "Global Communication Practice," a new model of the development of civilization based on "Global Communication Practice" has greatly expanded the living space of human civilization, it provides values coexistence and broad basement of identity. However, under the condition of imbalance in social development in the current regional, comprehensive national strength, increasing competition, new manifestations of various local conflicts of hegemonies and power politics from the time when the case volts, as countries are independent and apply different social 
systems, in particular social forms, the value represented a specific state and national interests is certainly very different values, and therefore, the value identity of these "universal" in the sense of these "universal" identity is actually very difficult to achieve. Present value recognition worldwide recognition is mainly above "dominant values" of sense.

\section{IDENTITY AND CONFLICT OF VALUE}

While Economic globalization is strengthening the value of identity, it doesn't diminish value conflicts. This is decided by diverse of value in the content of economic globalization. Under the background of economic globalization, diversification depends on the values of the following factors: First, economic globalization leads to the values of total time. In the context of economic globalization, it is showing increasingly intense contradictions and conflicts between national culture and exotic culture, the original values in different historical periods as well as the existence of different cultural backgrounds are squeezed on the same plane in the process of globalization, so domestic and foreign, both traditional and modern cultural values collide with each other, intertwined, showing a complex situation, and thus it highlights the diversity of values. Second, economic globalization leads to the values of richness. Open social environment has greatly expanded the field of activity of people and richened people's social life, it provides multifaceted perspective for people to observe issues, the result will inevitably lead to rich values. Third, economic globalization has exacerbated the values of complexity. Economic globalization make different values intertwined inextricably, showing a complex situation. In short, diverse, richness, complex of system of values is bound to exacerbate conflicts of different values.

Since the $21 \mathrm{st}$ century, the value conflict under the background of economic globalization has the following basic characteristics:

First, cross-border and inter-regional conflicts and domestic, regional conflicts staggered. Economic globalization broke the countries' boundaries, geographical and regional, ethnic and national boundaries, on the one hand,the global value exchange for recognition of the value expand the space, on the other hand, it also provides a place for collisions and conflicts of different values, but at Meanwhile, domestic conflict of values within the region has not diminished, and therefore, the conflict of values forming situation that cross-border conflicts and conflicts between inter-regional and within national, regional conflicts is interlocking under the background of economic globalization.

Second, the impact is broader, more subtle, and more acute contradictions. Since the values of the conflict are the background of economic globalization, cross-border and inter-regional conflicts and domestic, regional conflicts staggered, the impact of this conflict will be even more extensive. Moreover, the value of conflict taken placed in the process of the economic value of the globalization simultaneously are often more subtle.

Since the 19-20 century, the expansion of Western capitalism overseas and worldwide development of modern capitalism is such a process that a certain kind of value of forcedly into the world. In the context of economic globalization, mutual penetration of value identity and value conflicts even more significant, showing the value of identity has conflict, recognition has value conflicts, and they are integrated and inseparable.

First, the value of identity has conflict. As mentioned above, the value of identity on the background of economic globalization mainly as identity "dominant values" of sense, it is non-comprehensive, dynamic, and relative; therefore, conflict of recognition is inevitable. No diversity, no difference, it does not matter, "led"; section level, flow and temporary recognition process must be full of contradictions and conflicts. For example, the process of economic globalization greatly improved people's concept of competition, the concept of time and efficiency ideas, open concept and the concept of talent, knowledge, ideas, and other ecological concepts. These ideas led to the interest level values (such as awareness of the value of knowledge, benefit value conscious, value-conscious environment, focusing on the value of the reform and opening consciousness) identity, more and more countries and regions closer to the values of these modernization. However, this is yet inspire a new round of competition and conflict, countries, regions and regional, ethnic and national mutual openness, in the process of cooperation, it did not give up their own interests to safeguard their own interests protest, in which the value of conflict is inevitable.

Second, the value conflicts have recognition. As noted above, economic globalization is all-round communication and contact in regional ethnic countries, and it strengthened the convergence of interests. Thus, even if the social system is fundamentally different, national social ideology is fundamentally antagonistic, and there is often a certain common interests and common values between regional and national. Value conflicts exist in the value of identity is a unique phenomenon of economic globalization era. In this process, the dependence of the developed countries on developing countries will gradually increase the power of the developing countries, and it will continue to increase in international relations, the impact on global affairs will be increasing. Thus the interests of the developed countries and the interests of developing countries are often closely linked.

\section{FACING RECOGNITION AND VALUE CONFLICT CORRECTLY}

In contemporary Chinese society in transition, on the one hand, it faces the challenges of accession to WTO; on the other hand, it carries a heavy burden of history, the value conflicts between tradition and modernity, and the value conflicts between the local communities and outside the domain is more acute. To properly treat the value of identity and value conflicts under the background of economic globalization, to explore the construction of the mechanism in line with the values of the world's cultural development trend of China's transition, the following points should be noted: First, establish broaden their horizons, actively integrate into the global recognition of the value of the trend. An important achievement of economic globalization is that greatly expand the living space of human civilization. The 
so-called "survival of human civilization" is much more than a geographical concept, but it a concept of human practices, lifestyle and way of thinking. Expansion of economic globalization on human civilization living space is a landmark historic leap and progress reflecting the survival and development of human civilization. This leap and progress is comprehensive, it covers economic, political and cultural aspects. Therefore, the building of values of the modern era must also adapt to historic progress on this way of development of human civilization. Global communication practice, the widespread of modern education, science, culture, outstanding achievements of all ethnic groups in the construction of spiritual civilization and rewarding experience learn from each other, all mankind spiritual wealth of human culture, all these, it strengthens the global characteristics of the modern era values. To expand the human spirit of space, you must overcome the narrow horizons. In the era of economic globalization, the development of human spirit and build of values, absorbing mankind's cultural achievements is more inseparable. Therefore, the establishment of open horizons, to expand humanistic spirit of space, it is essential for the construction of the conditions under the age of globalization values. We should have a deep understanding of present different model of social development and study the different models of civilization thoroughly, especially modern social values on behalf of the development direction and accepted by whole world, we should establish scientific in the process of building values. .

Second, uphold the values of the dominant role of the advanced guard against cultural imperialism. As described above, owing to ideology opposition representing different social systems, the global recognition of the value can not be denied confrontation and conflict of values and cultural ideas. In countries, ethnic and national cultural exchange, each side is trying to maintain their own independent interests and cultural identity, in fact it needs to safeguard national interests and national dignity, it also need to maintain the traditional nation. In international relationship, a country wish to dominate the world, in addition to the military, political, economic expansionism, it doesn't forget the external expansion in culture. They tend to market and sell values representing their interests in the name of "universal value" in an attempt to dominate the world .Thus, in pioneering the development of humanistic spirit of space; we must vigorously promote the national culture and resist the cultural imperialism. we should handle properly the relationship between achievements of civilization, we absorb extensively from worldwide and development of the socialist-led culture and stick to the cultural direction of socialism with Chinese characteristics; we must properly handle the relationship between tradition and creations and inspire the whole national identity and pride of national culture, we should love of the Chinese nation with a long history and splendid culture, and vigorously carry forward the spirit of patriotism, we should preserve national dignity. To alert fawning and resurgence of enslaving ideological and to alert the behavior of denying history, the number of national nihilism who is forgotten ancestors is rise vigilance deny the socialist orientation, detractors thought the spread of Marxist ideology. Adhere to the leading role of socialism with Chinese characteristics in the process values of the construct values.

Third, establish proactive dialogue awareness; strengthen the role of science external radiation values. Values in the integration of international is not unidirectional, but bidirectional. In order to integrate into the world cultural trend, we not only need to be open-minded, but also to absorb beneficial foreign values extensively; and the need to take the initiative to strengthen the role of the national external radiation of their scientific values. Globalization means more intense competition in all aspects, if they not to strengthen the role of the national external radiation of their scientific values, their values will be lost in the tide of world culture; once we lost counterweight and peer status to foreign values ,bidirectional integration of values become a "one-way annexation." China is in the period that has the most conflicts and the fastest changes currently in the history of the Chinese nation, it also in the fastest period of development. Many in the planned economy period applicable values rapid retreat, and the new values applied to a socialist market economy is still being formed, yet mature; moral confusion and a crisis of faith are always appearing, this is a confusion of values easiest period. Of course, the foundation of culture, including values lies in the development of socio-economic and political development; but we can not ignore the guiding role of human values and the huge reaction of socio-economic and political.

\section{CONCLUSION}

Guided by the important Thought of "Three Represents", and timely explore, to establish a value system with characteristics of the times and Chinese characteristics, and consistent with the direction of development of world civilization value system is our major tasks placed in front of us.

\section{References}

[1] Wang Xinyan balls of the value of identity and studies on analysis of values conflict, 2002.11

[2] [US] Paul Kurtz • Humanitarian Oriental Publishing ceremony of the 21st century, 1998.

[3] [US] Alvin Toffler's Future Shock • Xinhua published, 1996. 